\title{
Chasing the Red Queen
}

THE EVOLUTIONARY RACE BETWEEN AGRICULTURAL PESTS AND POISONS

Andy Dyer

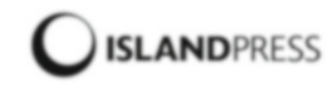

Washington | Covelo | London 


\section{Copyright (C) 2014 Andy Dyer}

All rights reserved under International and Pan-American Copyright Conventions. No part of this book may be reproduced in any form or by any means without permission in writing from the publisher: Island Press, 2000 M Street, NW, Suite 650, Washington, DC 20036.

ISLAND PRESS is a trademark of the Center for Resource Economics.

Library of Congress Control Number: 2014942401

Printed on recycled, acid-free paper $\odot$

Manufactured in the United States of America

10987654321

Keywords: Island Press, pesticide resistance, microbial ecology, sustainable agriculture, eco-agriculture, monoculture, trophic cascades, biotechnology, genetics, Darwin, Roundup 


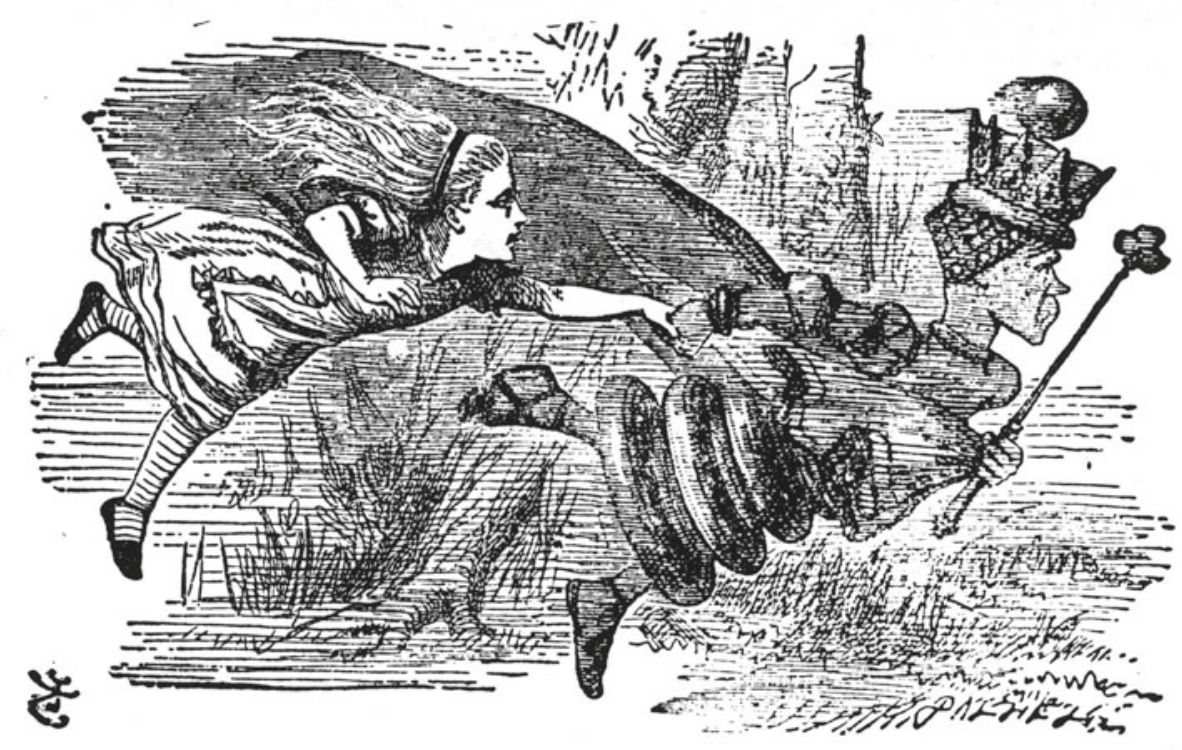

"Well, in our country", said Alice, still panting a little, "you'd generally get to somewhere else - if you ran very fast for a long time, as we've been doing."

"A slow sort of country!" said the Queen. "Now, here, you see, it takes all of the running you can do to keep in the same place. If you want to get somewhere else, you must run at least twice as fast as that!" -Lewis Carroll, Through the Looking-Glass, 1871 



\section{CONTENTS}

Preface

$\mathrm{xi}$

\section{PART I: INTRODUCING THE RED QUEEN}

Chapter 1 The Never-Ending Race: Adaptation and Environmental Stress

Box 1-1: All the genetics you'll need 9

Box 1-2: The scale of evolution $\quad 12$

Chapter 2 The Evolution of Farming: Scaling Up Productivity 15

Box 2-1: Patches, pests, and time lags $\quad 17$

Chapter 3 Survival of the Fittest: Darwin's Principles 33

Box 3-1: Exponential growth 36

\section{PART II: IGNORING THE RED QUEEN}

Chapter 4 Reductionist Farming: Losing Ecosystem Services

Box 4-1: Secondary compounds and crop plants

Chapter 5 A Weed by Any Other Name: Monocultures and Wild Species

Box 5-1: Adaptations, plasticity, and mutations

Chapter 6 Running Faster: Insecticide and Herbicide Resistance

\section{PART III: TRYING TO BEAT THE RED QUEEN}

Chapter 7 Exercises in Futility: Cases of Resistance

Box 7-1: Hidden mutations for resistance

Chapter 8 King Cotton vs. the Red Queen

Box 8-2: Cotton varieties 
$\mathrm{x}$ Contents

Chapter 9 The Cornucopia of Maize vs. the Red Queen 107

Box 9-1: Who is the enemy? 112

Box 9-2: Corn varieties 115

Chapter 10 The Red Queen Trumps Technology:

The Failures of Biotech 117

Box 10-1: Getting ready for the Roundup 125

Box 10-2: Advanced genetic issues 129

PART IV: PLAYING THE RED QUEEN

Chapter 11 Understanding the Chase to Escape the Cycle 135

Chapter 12 Slowing the Race by Slowing the Attack 143

Box 12-1: How gene flow influences pesticide resistance 148

Chapter 13 Ecosystem Farming: Letting Nature do the Work 159

Box 13-1: Jack of all trades or master of one? 164

Box 13-2: Living soil 168

Chapter 14 Integrated Systems and Long-Term Stability 173

Chapter 15 Epilogue: Putting All of Our Eggs in a Diversity 189 of Baskets

Notes 193

Index 211 
Our mental image of a farm is a peaceful setting with fields of wheat or corn gently waving in the afternoon breeze and a farmer driving a tractor, patiently tending the crops until they are ready for harvest. This tranquil scene comes not from personal contact with agriculture, which most of us don't have, but primarily through the imagination and exaggeration of Hollywood. In truth, farming is very hard work with long days that often begin before dawn and end after dark. In contrast to the bucolic Hollywood scenes, the farm is often more like a battlefield, with the farmer spending much of his or her time and energy in a war with nature.

The enemies are insects, mites, bacteria, fungi, nematodes, and any number of microbes that chew, suck, tunnel, infect, and otherwise reduce the vitality of the crop plants. This battle began about 10,000 years ago with the dawn of agriculture, and it takes place, in some form, in every human culture. But today, farmers are losing their foothold - and the war is growing ever more expensive. It is increasingly difficult to farm economically on a small scale; feeding the world has become an enormous industrial enterprise, practiced intensively, with ever more advanced equipment and technology.

Part of the problem is that we have been remarkably successful at making our food crops desirable not just to us, but to many, many other species. We've ramped up the sweetness and juiciness of fruits, the quantity of starches in grains, the proportions of proteins and fats in seeds, the overall yield of crops. Many of today's fruits and grains bear faint resemblance to their wild progenitors. We find ourselves fending off the rest of nature because we usually grow these tasty plants in vast single-species stands and make every 
attempt to eliminate all other competing species in the fields. Like us, the many species of crop pests are eager to take advantage of these incredibly abundant, incredibly palatable, and increasingly vulnerable resources.

To combat these pests, the weapons of agriculture have grown increasingly lethal, from elemental compounds and plant extracts a century ago to potent synthetic herbicides and pesticides today. Yet modern farmers have no more success against weeds and other invaders than their ancestors did several generations ago. And in addition to being more expensive, synthetic pesticides are more damaging to the environment. Each growing season, farmers use the latest chemicals and technology to protect their crops, yet the goal of long-term control of crop pests remains elusive. Instead, the pests simply adapt, becoming increasingly resilient to an increasingly costly succession of pesticides. In addition, there is tremendous collateral damage to many other organisms in and around the fields and in the soil; many of these organisms are necessary for their contributions to the health of the environment. This collateral damage has important and long-term effects on our ability to maintain farm productivity.

The constant struggle to control crop losses can be described in military terms as a battle, but an even better analogy comes from Lewis Carroll's Through the Looking-Glass. ${ }^{1}$ The Red Queen explains to Alice that, in Wonderland, a person must run very fast just to stay in the same place-a metaphor that biologists have borrowed to explain the process of coevolution. In biology, the Red Queen Hypothesis describes how an organism adapts to an environmental stress, such as the actions of a second organism, which elicits a counteradaptation in the second organism. The result is that both sides are continuously adapting and counteradapting to each other. In such an "evolutionary arms race" there is no winner, only a neverending race without a finish line.

This is the situation in which farmers currently find themselves. As new pesticides are produced and applied to kill unwanted organisms, the targeted pests adapt to each new chemical, which requires the development of new chemicals, which stimulates 
further adaptation, and so on. For 60 years, farmers have become increasingly entrapped by what has been termed a "chemical dependency treadmill.” To break the cycle, we must first recognize the biology behind it. This book will explore the central problem of modern agriculture-pest resistance-by applying the principles of evolutionary biology. We will use the Red Queen Hypothesis as a mental construct for understanding the way species and populations reduce environmental stress by adapting to it. More importantly, the Red Queen Hypothesis will help us understand why the use of chemical controls has no real end point and why there is no realistic chance of winning the war against crop pests.

Most of us have at least some familiarity with efforts to control, and even eradicate, the creatures who are trying relentlessly to eat our food before we can. Those efforts are the result of billions of dollars spent on research and development by agrochemical companies to provide farmers and ranchers with the chemical tools they need to kill agricultural pests, including weeds, insects, and disease-causing pathogens. We can also appreciate that chemical companies, like any other business, are economic competitors and must produce better and different chemicals as part of their effort to maintain market share and corporate earnings. What many of us may not realize is that evolutionary biology drives the entire process and restricts the success of any and all efforts at pest control. The rules of engagement, essentially the rules of the evolutionary war, will be described in this book.

This conversation extends well beyond our attempts to control pests and must also focus on protecting soil and biodiversity, and on sustainable farming such that we are able to maintain our capacity to produce food into the future. While agriculture has always been the backbone of the American economy, it is now producing goods for a growing range of sectors of the economy completely unrelated to food. For example, corn (maize) has always been a vital commodity in American agriculture, but the production of ethanol is now the largest "consumer" of corn in America, and additional products derived from corn include plastics, explosives, insecticides, 
adhesives, dyes, construction materials, paints, and paper products. Corn production now has a life of its own beyond providing food for humans and livestock, and our economy is increasingly reliant on this single crop. Therefore, any threat to current levels of farm production has far-reaching consequences, and protecting that productivity by any means possible has become a national priority. It is perhaps ironic that we may ultimately have less to fear from terrorism or trade barriers or market manipulation in agriculture than we do from multitudes of tiny organisms that are completely indifferent to our economic status or national goals. And we have to be concerned because we have been largely unsuccessful at dictating the terms of this battle.

The no-win scenario of the Red Queen has not been applied to chemical pest control in agriculture even though chemical resistance and the evolutionary process behind it are very well known and have been documented in everything from bacteria and fungi to mosquitoes and nematodes. However, as our technological capacity has expanded, our creative attempts to control pests have also expanded. Today, an entire industry is oriented around developing genetically modified plants that can withstand the toxic effect of specific herbicides, yet we are already faced with the emergence of weeds that are resistant to those herbicides. Thus, despite our apparent understanding of evolutionary biology, we are failing to recognize that agriculture is not exempt from the same rules that govern all living things. My goal with this book is to convince the reader that, despite the enormous commitment of time, money, and expertise to the development of chemical and biochemical approaches in pest control, the race with the Red Queen is not a race that can be won.

The Red Queen Hypothesis offers a simple yet profound tool for helping us understand how nature works in relation to the problems we continually encounter in agriculture. Just as important, this understanding also offers us a direction for how we can move from fighting nature to benefiting from it in the business of food and fiber production. Increasingly, we see that adhering to the rules of ecology and evolutionary biology may be the key to managing agricultural 
productivity. This book provides a few historical and contemporary examples in which farmers and resource managers work with natural processes to strengthen agriculture by integrating crop plants into a healthier farm ecosystem. By doing so, they reduce or even eliminate the need for artificial chemicals, whether pesticides or fertilizers, and regain a more natural control over crop pests.

The concept of the Red Queen concept is simple, but I want to acknowledge that the problem of pesticide resistance is complex. The scope of this book does not allow me to explore all the intricacies of the concepts I discuss, and I hope that knowledgeable readers will excuse any simplifications. After asking colleagues from different disciplines in biology to review the text of this book, I recognize that my views may differ from those of some others, but that's part and parcel of the process of science. I would like to gratefully acknowledge friends and colleagues for constructive comments on this book as it was being developed: Kevin Rice, Buz Kloot, Ray Archuleta, Nathan Hancock, Michele Harmon, Hugh Hanlin, Garriet Smith, Bill Jackson, and Derek Zelmer, as well as my students Alyssa Smith and Brandy Bossle. 